\title{
Propagação vegetativa da corticeira-da-serra (Erythrina falcata Benth.) por estaquia caulinar e foliar
}

\author{
Vegetative propagation of the Brazilian coral \\ (Erythrina falcata Benth.) by stem and foliar cutting
}

\author{
Leonildo Betanin ${ }^{1}$; Alexandre Augusto Nienow ${ }^{2 *}$
}

\section{Resumo}

Com elevado potencial de uso ornamental e na recuperação de áreas de preservação permanentes e degradadas, a corticeira-da-serra apresenta, no entanto, baixa capacidade de regeneração natural e dificuldades na formação de sementes para a produção de mudas. A propagação vegetativa, assim, se apresenta como alternativa. O estudo, conduzido em estufa com nebulização intermitente, teve por objetivos avaliar a sobrevivência e a capacidade de enraizamento de estacas caulinares (sem folhas) coletadas na primavera e no outono, e foliares na primavera, e o efeito dos tratamentos com AIB ( 0 , 1000,2000 e $3000 \mathrm{mg} \mathrm{L}^{-1}$ ). O delineamento experimental foi em blocos casualizados, com quatro repetições e doze estacas por parcela. As estacas foliares (trifoliadas) foram preparadas retirando-se os dois folíolos laterais e reduzindo pela metade o folíolo apical, no primeiro ano, e reduzindo pela metade os dois folíolos laterais no segundo ano. A estaquia foi realizada em bandejas alveoladas de isopor, de 72 células, com substrato de casca de arroz carbonizada (50\%) + fibra de côco (50\%) (v/v). Estacas caulinares herbáceas sem folhas apresentaram elevada mortalidade e ausência de enraizamento na primavera e no outono. Estacas foliares mantendo-se dois folíolos laterais reduzidos à metade, com aplicação de AIB, apresentaram enraizamento de 35,4\%.

Palavras-chave: Mudas, estacas, enraizamento, ácido indolbutírico, AIB

\begin{abstract}
With high potential for ornamental use and permanent preservation in degraded areas, the Brazilian coral presents low capacity of natural renovation and has difficulties to produce seeds for seedling production. The vegetative propagation, thus, is presented as an alternative. The study, carried out in a greenhouse with intermittent nebulization system, aimed to assess the survival and the rooting capacity of stem (without leaves), collected in the spring and autumn, and foliar cuttings in the spring, and the effect of the treatments with IBA $\left(0,1000,2000\right.$ and $\left.3000 \mathrm{mg} \mathrm{L}^{-1}\right)$. The experimental design was the casualized blocks, with four replications and twelve cuttings by parcel. The foliar cuttings (trifoliar) were prepared by removing the two lateral folioles and reducing the apical foliole by half in the first year; and reducing the two lateral folioles by half and removing the apical foliole in the second year. The cutting was carried out in polystyrene alveolated trays of 72 cells, with of carbonized rice shells $(50 \%)+$ coconut fiber $(50 \%)(\mathrm{v} / \mathrm{v})$ substrate. Herbaceous stem cuttings without leaves presented hight mortality and lack of rooting in the spring and autumn. Foliar cuttings with the two lateral folioles reduced by half with IBA application presented rooting of $35.4 \%$.
\end{abstract}

Key words: Cuttings, rooting, indolbutiric acid, IBA

1 Biólogo, Professor, Mestre pelo Programa de Pós-graduação em Agronomia da Universidade de Passo Fundo. E-mail: 1betanin@ yahoo.com.br

2 Engenheiro Agrônomo, Doutor, Professor de Fruticultura e Silvicultura da Faculdade de Agronomia e Medicina Veterinária da Universidade de Passo Fundo. E-mail: alexandre@upf.br

* Autor para correspondência 


\section{Introdução}

A crescente demanda de plantas nativas para fins ornamentais, bem como para a recuperação de matas ciliares ou áreas degradadas, vem despertando o interesse de viveiristas pela produção de mudas de várias espécies. Contudo, a dificuldade de obtenção de sementes e de sucesso nas técnicas de propagação, entre outros fatores, tem conduzido a uma insuficiente disponibilidade de mudas de algumas espécies.

A corticeira-da-serra (Erythrina falcata Benth.) é uma espécie arbórea encontrada no Brasil, Argentina, Bolívia, Paraguai e Peru. No Brasil, ocorre desde a Bahia até o Rio Grande do Sul, em ecossistemas que variam de florestas úmidas a decíduas e semidecíduas, e também no cerrado. Parte do interesse por esta espécie está relacionada ao valor ornamental das flores vermelhas a alaranjadas, produtoras de néctar, atrativas à avifauna, para utilização em vias públicas, parques e jardins. Pode também ser usada em sistemas agroflorestais, na recuperação de matas ciliares e ecossistemas degradados, e em locais com frequente inundação durante o ano (CARVALHO, 2003).

Em ambiente natural, a dificuldade da propagação natural, por sementes, apesar da elevada quantidade de flores formadas, é confirmada pela baixa ocorrência de indivíduos jovens na área ocupada por árvores adultas.

A corticeira-da-serra é, basicamente, autoincompatível, polinizada por pássaros, sendo que, em condições naturais, somente $20 \%$ dos óvulos disponíveis produzem sementes, com apenas $1 \%$ das flores transformadas em frutos (ETCHEVERRY; ALEMÁN, 2005). Além disso, a espécie apresenta o fenômeno conhecido como cleistogamia, ou seja, a maioria das flores não apresenta a abertura das pétalas para permitir a polinização cruzada.

Apesar da dificuldade de produção de sementes, e dos danos às mesmas provocados por ataque de brocas (CARVALHO, 2003), a produção de mudas ainda é realizada por sementes. Os frutos são colhidos da árvore quando adquirem a coloração preta e iniciam a queda espontânea, e a emergência ocorre em 4 a 8 dias, com taxa de germinação superior a 90\% (LORENZI, 2002).

Diante da dificuldade de se realizar a propagação sexuada, as técnicas de propagação vegetativa se apresentam como alternativas. Dentre os métodos, a estaquia possui a vantagem de garantir a reprodução das características de genótipos superiores; reduzir o período de juvenilidade, ou seja, o tempo até as plantas iniciarem a fase reprodutiva (floração e frutificação), desde que utilizadas estacas de matrizes já diferenciadas para tanto; além de permitir elevada produção de mudas em tempo e espaço reduzido. As desvantagens incluem a dificuldade de se induzir raízes adventícias em muitas espécies.

A viabilidade do uso da estaquia na propagação, com objetivo comercial, depende da facilidade de enraizamento da espécie/cultivar, da qualidade do sistema radicular formado e do desenvolvimento posterior da planta (FACHINELLO; HOFFMANN; NACHTIGAL, 2005).

Fatores internos e externos à planta matriz ou às estacas podem interferir no processo de enraizamento. São considerados fatores internos as condições fisiológicas da planta matriz, a idade da planta ou das estacas, o tipo de estaca (apical, mediana ou basal; herbácea, semi-lenhosa ou lenhosa), a época de coleta, o potencial genético de enraizamento, a sanidade da planta, o balanço hormonal e a possibilidade de oxidação de compostos fenólicos. Como fatores externos citamse a temperatura, a luz, a umidade, o substrato e os condicionamentos (lesão na base da estaca e a aplicação de reguladores de crescimento). De modo geral, a interação entre esses fatores permite melhor explicar as causas do enraizamento, ou seja, quanto mais difícil o enraizamento de uma espécie ou cultivar, maior será a importância dos fatores envolvidos (FACHINELLO; HOFFMANN; NACHTIGAL, 2005). 
A formação de raízes adventícias em estacas envolve várias substâncias, mas as auxinas são as de maior efeito no enraizamento, cuja síntese ocorre nas gemas apicais e folhas novas. A auxina natural das plantas é o ácido indol-3-acético (AIA). O ácido indol-3-butírico (AIB), embora menos abundante que o AIA, ocorre também naturalmente nas plantas. Dentre os reguladores de crescimento (sintéticos), os mais eficientes e utilizados são o ácido AIB e o ácido naftalenoacético (ANA), sendo o AIB tido como o mais eficiente. Há trabalhos que demonstram que a aplicação exógena de AIB sintético pode, no tecido vegetal, simplesmente elevar a sua concentração interna ou se converter parcialmente em AIA. O AIB pode, ainda, apresentar efeito sinérgico, modificando a ação ou a síntese do AIA ou aumentar a sensibilidade dos tecidos ao AIA. No entanto, a concentração ideal está na dependência de diversos fatores e varia de acordo com a espécie e cultivar a ser reproduzida (HARTMANN et al., 2002).

Os cofatores de enraizamento são substâncias de ocorrência natural que atuam sinergicamente com as auxinas, sintetizadas também em gemas e folhas jovens, destacando-se a importância da manutenção, em muitas espécies, das folhas e gemas em atividade vegetativa para a produção de reguladores de crescimento e nutrientes (FACHINELLO; HOFFMANN; NACHTIGAL, 2005).

A presença de folhas nas estacas é um forte estímulo para a formação deraízes, mas a transpiração se torna mais elevada. Em espécies de fácil enraizamento, a rápida formação de raízes permite que a absorção de água compense a quantidade perdida pela transpiração (HARTMANN et al., 2002). Para minimizar a transpiração, é adotado um sistema de irrigação por nebulização, que proporciona a formação de uma película de água na superfície da folha (PAIVA; GOMES, 2001), além de reduzir a temperatura do ar e do tecido vegetal, e manter o substrato úmido.

O objetivo deste trabalho foi avaliar o enraizamento de estacas caulinares e foliares de
Erythrina falcata Benth., coletadas na primavera e no outono, e o efeito do tratamento com AIB.

\section{Material e Métodos}

A pesquisa, dividida em dois experimentos, foi desenvolvida no Setor de Horticultura da Faculdade de Agronomia e Medicina Veterinária (FAMV) da Universidade de Passo Fundo (UPF).

Os experimentos foram realizados em uma estufa medindo $210 \mathrm{~m}^{2}$, com 2,5 m de altura (pé direito), em estrutura de alumínio galvanizado, teto em arco, revestida com polietileno de baixa densidade (PEBD), dotada de cortinas laterais móveis, instalada no sentido nordeste-sudeste. Para a redução da temperatura e a insolação, foi instalada uma tela tipo sombrite, com capacidade de $75 \%$ de sombreamento, disposta internamente a $2,5 \mathrm{~m}$ de altura e nas laterais.

O sistema de irrigação, do tipo intermitente, constava de seis linhas distanciadas de $1,5 \mathrm{~m}$, com bicos nebulizadores dispostos a cada $1 \mathrm{~m}$. O sistema, controlado por um timer, era acionado a cada 10 minutos, com período de molhamento de 8 segundos.

As estacas foram retiradas de 28 plantas matrizes oriundas de semente, com idade de dois anos, mantidas em vaso sob nebulização intermitente na estufa onde foram realizadas as estaquias. Para estimular brotações laterais, utilizadas como estaca, a altura das plantas e dos ramos secundários foi reduzida em torno de $1 / 3$ cerca de um mês e meio antes da coleta, bem como realizada adubação com $200 \mathrm{~g}$ de uréia por matriz.

As coletas das estacas e a estaquia foram realizadas no período da manhã. Após a coleta, as estacas foram submetidas à desinfecção mediante imersão, por 5 minutos, em hipoclorito de sódio a $0,6 \%$, com posterior lavagem em água corrente. No preparo das soluções de AIB, o produto puro $\left(\mathrm{C}_{12} \mathrm{H}_{13} \mathrm{NO}_{2}\right.$ - cristalino), da marca Vetec, foi primeiramente dissolvido em $50 \mathrm{~mL}$ de álcool etílico 
$98^{\circ} \mathrm{GL}$, e o volume da solução completado até 100 $\mathrm{mL}$ com água destilada. $\mathrm{O}$ tempo de imersão da base das estacas $(3 \mathrm{~cm})$ nas soluções concentradas foi de 5 segundos.

A estaquia foi realizada em bandejas alveoladas de isopor, com 72 células, utilizando como substrato casca de arroz carbonizada (50\%) + fibra de côco $(50 \%)(\mathrm{v} / \mathrm{v})$. As estacas foram enterradas a uma profundidade média de $4 \mathrm{~cm}$. Durante a condução dos experimentos não foram realizados tratamentos fitossanitários.

Experimento 1-Propagação da corticeira-da-serra (Erythrina falcata Benth.) por estaquia caulinar

A estaquia foi realizada em duas épocas, ou seja, em 03/12/2005, no final da primavera, e em 13/04/2006, no outono. As estacas caulinares herbáceas foram padronizadas com $15 \mathrm{~cm}$ de comprimento e $0,8 \mathrm{~cm}$ de diâmetro, em média, eliminando-se as folhas, cortando em bisel na porção superior, logo acima de uma gema, e reto na extremidade basal.

As estacas foram submetidas a tratamentos com AIB nas doses de 0, 1000, 2000 e $3000 \mathrm{mg} \mathrm{L}^{-1}$. O delineamento experimental utilizado foi em blocos casualizados, com quatro repetições e 12 estacas por parcela. Após 18 e 34 dias, na estaquia de primavera, e 33, 48, 64 e 76 dias, na estaquia de outono, foi avaliada a porcentagem de estacas vivas. Ao final do experimento de outono (76 dias) foi avaliado, também, o número de estacas enraizadas, e o número e comprimento de raízes.

Experimento 2 - Propagação da corticeira-da-serra (Erythrina falcata Benth.) por estaquia foliar

A estaquia foi realizada no final das primaveras de 2005 e 2006 (01/12/2005 e 24/11/2006). Em 2005, as estacas foliares (trifoliadas) foram preparadas retirando os dois folíolos laterais e reduzindo em $50 \%$ o folíolo apical. Em 2006, os dois folíolos laterais foram reduzidos em $50 \%$ e eliminado o apical.

As estacas foram submetidas a tratamentos com AIB nas doses de 0, 1000, 2000 e $3000 \mathrm{mg}$ $\mathrm{L}^{-1}$. O delineamento experimental foi em blocos casualizados, com quatro repetições e 12 estacas por parcela.

$\mathrm{Na}$ estaquia realizada em 2005 foi avaliada a porcentagem de estacas vivas aos 21 e 34 dias. Em 2006, foi determinada a porcentagem de estacas vivas aos 27, 43 e 60 dias após a estaquia e, aos 60 dias, a porcentagem de estacas enraizadas e massa fresca de raízes por estaca.

Naanáliseestatística,paraosdoisexperimentos,os dados de porcentagem obtidos foram transformados em arc seno [raiz $(x+0,5 / 100)]$ e submetidos à análise de variância. Quando significativa, as diferenças entre médias foram comparadas pelo teste de Tukey a 5\% de significância utilizando o programa estatístico Estat - Sistema para Análises Estatísticas - versão 2.0 (Unesp/FCAV-Jaboticabal).

\section{Resultados e Discussão}

Experimento 1 - Propagação da corticeira-da-serra (Erythrina falcata Benth.) por estaquia caulinar

A sobrevivência das estacas caulinares foi considerada muito baixa nas duas épocas estudadas. $\mathrm{Na}$ estaquia realizada na primavera (Tabela 1), já aos 18 dias restavam 33,3\% de estacas vivas, não diferindo os tratamentos. Aos 34 dias, sem AIB e com $1000 \mathrm{mg} \mathrm{L}^{-1}$, a totalidade das estacas se apresentava morta, restando $12,5 \%$ e $22,9 \%$ de estacas vivas nos tratamentos com 3000 e $2000 \mathrm{mg}$ $\mathrm{L}^{-1}$ de $\mathrm{AIB}$, respectivamente. $\mathrm{O}$ enraizamento foi nulo nesta época. 
Tabela 1. Porcentagem de estacas caulinares vivas de corticeira-da-serra (Erythrina falcata Benth.) aos 18 e 34 dias após a estaquia na primavera (03/12/05), e aos 33, 48, 64 e 76 dias após a estaquia no outono (13/04/06), tratadas com doses de AIB. FAMV, Passo Fundo, RS

\begin{tabular}{|c|c|c|c|c|c|c|}
\hline \multirow{3}{*}{$\begin{array}{c}\text { Doses de AIB } \\
\left(\mathrm{mg} \mathrm{L}^{-1}\right)\end{array}$} & \multicolumn{6}{|c|}{ Estacas vivas ( \%) } \\
\hline & \multicolumn{2}{|c|}{ Estaquia em $03 / 12 / 05$} & \multicolumn{4}{|c|}{$\begin{array}{l}\text { Estaquia em 13/04/06 } \\
\end{array}$} \\
\hline & 18 dias & 34 dias & 33 dias & 48 dias & 64 dias & 76 dias \\
\hline 0 & $29,2^{\mathrm{ns}}$ & $0,0 \mathrm{~b}$ & $60,4^{\mathrm{ns}}$ & $45,8^{\mathrm{ns}}$ & $31,2^{\mathrm{ns}}$ & $22,1^{\mathrm{ns}}$ \\
\hline 1000 & 43,8 & $0,0 \mathrm{~b}$ & 60,4 & 49,9 & 35,4 & 10,7 \\
\hline 2000 & 31,2 & $22,9 \mathrm{a}$ & 47,9 & 37,5 & 22,9 & 10,4 \\
\hline 3000 & 29,2 & $12,5 \mathrm{a}$ & 54,2 & 43,7 & 33,3 & 10,7 \\
\hline Média & 33,3 & 8,8 & 55,6 & 44,2 & 30,6 & 17,6 \\
\hline CV $(\%)$ & 39,64 & 40,95 & 20,02 & 31,48 & 26,58 & 25,95 \\
\hline Desvio padrão & 18,54 & 8,12 & 15,21 & 20,79 & 13,90 & 6,64 \\
\hline
\end{tabular}

Médias seguidas de mesma letra não diferem entre si pelo teste de Tukey a $5 \%$ de significância. ${ }^{\text {ns }}$ - não significativo a $5 \%$ pela análise de variância.

Considerando que as estacas eram de consistência herbácea, apresentando brotação poucos dias após a estaquia, o resultado pode ser atribuído ao estresse térmico e possível desidratação proporcionado pela elevada temperatura a que foram submetidas (superior a $36{ }^{\circ} \mathrm{C}$ nos períodos mais quentes), mesmo utilizando cobertura com sombrite $(75 \%)$ e nebulização intermitente. Este comportamento é relatado por Fachinello, Hoffmann e Nachtigal (2005), afirmando que, mesmo sob sistema de nebulização intermitente, a perda de água pode ser a causa da mortalidade de estacas herbáceas. Neves et al. (2006), realizando na primavera a estaquia de estacas herbáceas de corticeira-da-serra, também verificaram a ocorrência de brotação uma semana após, com morte das estacas e brotações após 30 dias, possivelmente pela elevada taxa de transpiração das folhas jovens, que provocaram desidratação.

No presente trabalho, a desinfecção foi realizada com hipoclorito de sódio a $0,6 \%$, sem aplicação de pasta fúngica na extremidade das estacas, o que pode ter contribuído para a elevada mortalidade, além das elevadas temperaturas. Carpanezzi, Tavares e Souza (2001), estudando a estaquia de Erythrina cristagalli L. (corticeira-do-banhado), afirmam que a desinfecção das estacas é fundamental e, quando não realizada, pode ocorrer o escurecimento e a morte das estacas de cima para baixo, associado ao orifício da medula, que favorece o dessecamento e a entrada de patógenos. Os autores recomendam a imersão das estacas em hipoclorito de sódio a $2 \%$ seguido de imersão de metade do comprimento das estacas em fungicida sistêmico ( $0,25 \mathrm{~g}$ de benomyl por litro d'água) por 5 minutos. Indicam, ainda, no início e a cada dois meses, a aplicação na extremidade das estacas de pasta fúngica composta da mistura de $100 \mathrm{~g}$ de tinta látex e $0,5 \mathrm{~g}$ de benomyl.

Realizando a estaquia em período menos quente, no outono, esperava-se obter maior sucesso, mas o que se verificou foram resultados semelhantes ao da primavera (Tabela 1), exceto pelo fato das estacas permanecerem vivas por período mais prolongado. Nas datas avaliadas não foram observadas diferenças entre os tratamentos na porcentagem de estacas vivas, restando, em média, 55,6\%, 44,2\%, 30,6\% e $17,6 \%$ aos 33, 48, 64 e 76 dias, respectivamente.

Ao final do experimento, foi verificado que apenas quatro estacas apresentavam enraizamento, todas com aplicação de AIB, sendo três estacas apresentando uma raiz cada, medindo $8 \mathrm{~cm}, 4,7 \mathrm{~cm}$ e $4,3 \mathrm{~cm}$, respectivamente, e uma estaca com três raízes $(0,7 \mathrm{~cm}, 0,6 \mathrm{~cm}$ e $0,3 \mathrm{~cm}$ de comprimento).Variações na resposta da época de realização da estaquia, tipo 
de estaca e do uso do AIB sobre a sobrevivência e enraizamento foram verificadas por vários autores, nesta e em outras espécies. Carpanezzi, Tavares e Souza (2001) obtiveram melhores resultados de enraizamento em estacas mais jovens e finas (3 a $6 \mathrm{~mm}$ ) de Erythrina cristagalli L., oriundas de brotações de estacas mais grossas e de plantas adultas. Estacas grossas (30 a $50 \mathrm{~mm}$ ), retiradas da copa, mostraram baixo enraizamento, inferior a 40\%. Gratieri-Sossella, Petry e Nienow (2008), em Passo Fundo, RS, também na estaquia da Erythrina cristagalli L., concluíram que o uso de AIB reduziu a mortalidade de mini-estacas herbáceas coletadas de plantas jovens (com menos de um ano de idade) em janeiro, possivelmente por ter acelerado o processo de enraizamento das mesmas, que foi de $93,3 \%$. Por sua vez, utilizando estacas lenhosas, coletadas em junho, apenas 2,5\% do total de estacas enraizaram e, com estacas semilenhosas, coletadas em janeiro, a mortalidade foi total. Em todos os experimentos foram utilizadas estacas sem folhas.

$\mathrm{Na}$ estaquia da quaresmeira Tibouchina sellowiana, realizada por Bortolini (2006), testando doses de AIB na primavera, foi verificada maior mortalidade de estacas (40\%) sem o uso do AIB, em relação a 1500 e $3000 \mathrm{mg} \mathrm{L}^{-1}$. Porém, estudando outra espécie de quaresmeira (Tibouchina pulchra), Knapik et al. (2003) não observaram influência dos tratamentos de AIB e ácido bórico, na mesma época de estaquia, com média de $30 \%$ de mortalidade. No outono, por sua vez, diferenças entre os tratamentos não foram observadas pelos autores, com mortalidades de 60,4\% (BORTOLINI, 2006) e $54,3 \%$ (KNAPIK et al., 2003).

Neves et al. (2006) estudaram o enraizamento da corticeira-da-serra utilizando estacas herbáceas, semilenhosas e de rebrote, retiradas de plantas adultas, e estacas de mudas obtidas sexuadamente com sete meses de idade (50 cm de altura). A pesquisa foi conduzida nas quatro estações do ano e foram testadas concentrações de $\operatorname{AIB}(0,1500$ e $\left.3000 \mathrm{mg} \mathrm{L}^{-1}\right)$. Exceto nas estacas semilenhosas de inverno foram mantidos dois pares de folhas reduzidas pela metade. Os resultados demonstraram que a época de coleta e o tipo de estaca interferiram na porcentagem de sobrevivência e enraizamento, mas os tratamentos com AIB não apresentaram efeito significativo. As estacas oriundas de mudas foram as que proporcionaram maior sobrevivência $(60,9 \%$ a $86,9 \%)$ e enraizamento $(47,6 \%$ a $73,3 \%)$ após 45 dias, com destaque para as coletadas no verão, demonstrando a importância da juvenilidade da planta matriz. As estacas de rebrotes, coletadas no verão, apresentaram 20,4\% de enraizamento, e as herbáceas e semilenhosas enraizamento variando entre $0 \%$ e $5,8 \%$.

Os resultados obtidos, especialmente com as estacas de mudas, superam aos obtidos no presente trabalho, sendo necessário ressaltar, como diferenciais importantes, que as mudas utilizadas por Neves et al. (2006) eram mais jovens e foram mantidos dois pares de folhas pela metade nas estacas, o que deve ter contribuído para o melhor resultado. Conforme Fachinello, Hoffmann e Nachtigal (2005), possivelmente estacas provenientes de plantas mais jovens apresentam maior possibilidade de enraizamento pelo menor conteúdo de inibidores e aumento do conteúdo de cofatores. Por sua vez, a presença de folhas nas estacas contribui com a produção de fotoassimilados, auxinas e cofatores (HARTMANN et al., 2002).

Esta observação pode ser confirmada pelos próprios resultados obtidos por Neves et al. (2006), que verificaram maior retenção das folhas nas estacas oriundas de mudas e de rebrota, que justamente tiveram melhores resultados de enraizamento.

Resultados positivos da presença de folhas foram constatados também por Cunha, Wendling e Souza Júnior (2003), que verificaram, após 30 dias, maior sobrevivência e enraizamento de estacas mantendo um par de folhas reduzidas em $1 / 3$, em miniestacas (3 $\mathrm{cm}$ a $5 \mathrm{~cm}$ ) de E. falcata coletadas de minicepas, cultivadas em sistema hidropônico. O substrato utilizado foi casca de arroz carbonizada $(35 \%)+$ vermiculita fina $(30 \%)+$ substrato orgânico $(30 \%)$, 
sem aplicação de AIB. Wendling, Ferrari e Dutra (2005) e Cunha et al. (2008), realizando a estaquia da E. falcata nas mesmas condições anteriores, porém comparando miniestacas coletadas de minicepas jovens obtidas de sementes cultivadas em hidroponia e em tubetes, obtiveram alta porcentagem de enraizamento (média de 85,5\%), com as mudas prontas para plantio em 4 a 5 meses.

Knapik et al. (2003) e Bortolini (2006), respectivamente com as quaresmeiras Tibouchina pulchra e Tibouchina sellowiana, observaram estreita relação entre a morte das estacas caulinares e a abscisão das folhas no início do processo, apresentando enraizamento apenas aquelas que mantinham as folhas.

A influência positiva da presença das folhas em estacas caulinares foi constatada por outros autores, com diferentes espécies, como Pio et al. (2004), em estacas herbáceas de figueira, e Mindêllo Neto (2006), com o pessegueiro cv. Charme. Xavier, Santos e Oliveira (2003), comparando tipos de mini-estacas caulinares de cedro-rosa (Cedrela fissilis) verificaram que as estacas caulinares apicais desfolhadas apresentaram menor enraizamento $(37,5 \%)$ que as demais, com folhas, as quais variaram de $75 \%$ a $100 \%$ de enraizamento.

Fochesato et al. (2006), na estaquia do louro (Laurus nobilis L.), mantendo 0, 2 ou 4 folhas, obtiveram $100 \%$ das estacas mortas na ausência de folhas, enquanto com 2 e 4 folhas a mortalidade foi de $16,7 \%$ e $11,5 \%$, respectivamente. Os autores atribuíram ao esgotamento das reservas, por ocasião da brotação, e à ausência de hormônios produzidos nas folhas, a mortalidade total das estacas sem folhas.
Experimento 2 - Propagação da corticeira-da-serra (Erythrina falcata Benth.) por estaquia foliar

Na primavera de 2005 as estacas foram mantidas com apenas o folíolo apical reduzido em 50\%. Não houve enraizamento, com morte à medida que ocorria a queda do folíolo. A senescência foi rápida, com apenas 45,3\% de sobrevivência já aos 21 dias, e aos 34 dias 18,7\%, não diferindo os tratamentos nas datas avaliadas (Tabela 2). Após 34 dias a mortalidade prosseguiu, não restando estacas vivas.

$\mathrm{Na}$ primavera seguinte, em 2006, a estaquia foliar foi implementada desta vez com a eliminação do folíolo apical e redução em $50 \%$ do limbo dos dois folíolos laterais. Os resultados foram superiores aos obtidos na primavera anterior, quando foi mantido apenas o folíolo apical, reduzido em $50 \%$. A aplicação de AIB refletiu positivamente na sobrevivência das estacas (Tabela 2). Aos 27 dias após a estaquia, 72,9\% das estacas tratadas com $3000 \mathrm{mg} \mathrm{L}^{-1}$ de AIB se mantinham vivas, diferindo apenas da testemunha (33,3\%), sem AIB. Aos 43 dias, embora estatisticamente os tratamentos não tenham diferido (média de 43,1\%), foi observada a tendência de menor sobrevivência das estacas não tratadas com AIB. Aos 60 dias, como constatado aos 27 dias, as estacas com AIB permaneceram vivas em maior porcentagem $(37,5$ a 43,7\%), em relação à testemunha $(10,4 \%)$.

Ao final do experimento, verificou-se que o uso do AIB proporcionou um estímulo ao enraizamento das estacas foliares (Tabela 3), não diferindo as doses entre si $(37,5 \%$ a $45,8 \%)$. Nas estacas não tratadas, o enraizamento foi de apenas 8,3\%. Por sua vez, a maior massa fresca de raízes foi proporcionada pelo tratamento com $2000 \mathrm{mg} \mathrm{L}^{-1}$ de AIB (0,41 g), não diferindo das demais doses, mas superior ao sistema radicular das estacas testemunhas $(0,04 \mathrm{~g})$. 
Tabela 2. Porcentagem de estacas foliares vivas de corticeira-da-serra (Erythrina falcata Benth.) aos 21 e 34 dias após a estaquia na primavera, em 01/12/2005, mantendo o folíolo apical reduzido em 50\% (folíolos laterais eliminados), e aos 27, 43 e 60 dias após a estaquia na primavera, em 24/11/06, mantendo os dois folíolos laterais reduzidos em 50\% (folíolo apical eliminado), tratadas com doses de AIB. FAMV, Passo Fundo, RS

\begin{tabular}{lccccc}
\hline \multirow{2}{*}{$\begin{array}{l}\text { Doses de AIB } \\
\left(\mathrm{mg} \mathrm{L}^{-1}\right)\end{array}$} & \multicolumn{5}{c}{ Estacas vivas ( \%) } \\
\cline { 2 - 5 } & \multicolumn{2}{c}{ Estaquia em 01/12/05 } & \multicolumn{3}{c}{ Estaquia em 24/11/06 } \\
\cline { 2 - 5 } & 21 dias & 34 dias & 27 dias & 43 dias & 60 dias \\
\hline 0 & $29,6^{\mathrm{ns}}$ & $14,6^{\mathrm{ns}}$ & $33,3 \mathrm{~b}$ & $22,9^{\mathrm{ns}}$ & $10,4 \mathrm{~b}$ \\
1000 & 51,7 & 16,6 & $62,5 \mathrm{ab}$ & 52,1 & $43,7 \mathrm{a}$ \\
2000 & 47,9 & 20,8 & $62,5 \mathrm{ab}$ & 47,9 & $37,5 \mathrm{ab}$ \\
3000 & 52,1 & 22,9 & $72,9 \mathrm{a}$ & 49,9 & $39,6 \mathrm{a}$ \\
\hline Média & 45,3 & 18,7 & 57,7 & 43,1 & 32,8 \\
CV (\%) & 22,97 & 32,98 & 16,63 & 28,42 & 27,88 \\
Desvio padrão & 15,80 & 9,63 & 13,34 & 17,25 & 14,44 \\
\hline
\end{tabular}

Médias seguidas de mesma letra não diferem entre si pelo teste de Tukey a $5 \%$ de significância. ${ }^{\text {ns }}$ - não significativo a $5 \%$ pela análise de variância.

Tabela 3. Porcentagem de estacas foliares enraizadas de corticeira-da-serra (Erythrina falcata Benth.) e massa fresca de raízes por estaca aos 60 dias após a estaquia na primavera (24/11/06), mantidos os dois folíolos laterais reduzidos em 50\% (folíolo apical eliminado), tratadas com doses de AIB. FAMV, Passo Fundo, RS

\begin{tabular}{lcl}
\hline $\begin{array}{c}\text { Doses de AIB } \\
\left(\mathrm{mg} \mathrm{L}^{-1}\right)\end{array}$ & \multicolumn{1}{c}{$\begin{array}{c}\text { Estacas enraizadas } \\
(\%)\end{array}$} & $\begin{array}{c}\text { Massa fresca de raízes } \\
(\mathrm{g})\end{array}$ \\
\hline 0 & $8,3 \mathrm{~b}$ & $0,04 \mathrm{~b}$ \\
1000 & $37,5 \mathrm{a}$ & $0,24 \mathrm{ab}$ \\
2000 & $37,5 \mathrm{a}$ & $0,41 \mathrm{a}$ \\
3000 & $45,8 \mathrm{a}$ & $0,27 \mathrm{ab}$ \\
\hline Média & 22,5 & 0,24 \\
CV $(\%)$ & 25,63 & 55,40 \\
Desvio padrão & 11,86 & 0,13 \\
\hline
\end{tabular}

Médias seguidas de mesma letra não diferem entre si pelo teste de Tukey a 5 \% de significância.

Gratieri-Sossela, Petry e Nienow (2008), testando o enraizamento de estacas foliares de Erythrina cristagalli L., coletadas no verão (primeira semana de março) de plantas jovens e adultas, em substrato de casca de arroz carbonizada (CAC) e solo+CAC+composto orgânico $(2: 1: 1)$, obtiveram também baixa porcentagem de enraizamento sem o uso de AIB (1,4\%).

Os melhores resultados obtido na segunda estaquia, com dois folíolos laterais reduzidos à metade, possivelmente está associado à maior produção de fotoassimilados, auxinas e cofatores, ainda que tenha ocorrido resposta à aplicação de AIB. Esta justificativa pode ser reforçada comparando com as estacas mantidas com menor área foliar, ou seja, com apenas um folíolo (apical) reduzido à metade, que apresentaram alta mortalidade e ausência de enraizamento, ainda que a estaquia tenha sido realizada em outro momento, na primavera de 2005.

Apesar do relativo sucesso no enraizamento de estacas foliares, comparativamente com as estacas 
caulinares, não foi verificada nenhuma estaca brotada durante o período de realização da estaquia, o que sugere a inexistência ou impossibilidade das folhas formarem gemas vegetativas, capazes de regenerarem uma planta. Por sua vez, o maior potencial de enraizamento das estacas foliares corrobora para destacar a importância da presença de folhas nas estacas caulinares, que por terem sido retiradas, muito possivelmente tenham prejudicado o enraizamento nesta pesquisa. O efeito benéfico das folhas é relatado por Hartmann et al. (2002), citando que a presença pode proporcionar melhor enraizamento, pois são fontes de promotores de enraizamento (auxinas e cofatores) e de fotoassimilados. O excedente da síntese de energia e nutrientes, deduzindo os gastos no processo respiratório, é canalizado para a iniciação e o desenvolvimento do sistema radicular. Porém, ressaltam que a presença de folhas pode ser importante no enraizamento, mas a retenção de folhas é mais uma conseqüência do enraizamento que um pré-requisito para que o mesmo ocorra.

Os experimentos conduzidos e outros consultados indicam que a juvenilidade das matrizes e a presença de folhas nas estacas são fatores determinantes no sucesso da propagação por estaquia. Porém, outros trabalhos devem ser conduzidos no sentido de aprimorar a técnica e elevar a porcentagem de estacas enraizadas.

\section{Conclusões}

Estacas caulinares herbáceas sem folhas de corticeira-da-serra apresentam elevada mortalidade e ausência de enraizamento na estaquia em final de primavera e início de outono, com sobrevivência pouco maior no outono, em razão das temperaturas mais amenas.

Estacas foliares mantendo-se dois folíolos laterais reduzidos à metade, com aplicação de AIB, apresentam enraizamento médio de 35,4\%.

\section{Referências}

BORTOLINI, M. F. Uso do ácido indol butírico na estaquia de Tibouchina sellowiana (Cham.) Cogn. 2006. Dissertação (Mestrado em Ciências - Produção Vegetal) - Faculdade de Agronomia. Universidade Federal do Paraná, Curitiba.

CARPANEZZI, A. A.; TAVARES, F. R.; SOUSA, V. A. de. Estaquia de corticeira-do-banhado (Erythrina crista-galli L.). Colombo: Embrapa Florestas, 2001. (Comunicado técnico, 64).

CARVALHO, P. E. R. Espécies arbóreas brasileiras. Brasília: Embrapa Informação Tecnológica; Colombo: Embrapa Florestas, 2003. v. 2. 1036 p.

CUNHA, A. C. M. C. M. da; WENDLING, I.; SOUZA JÚNIOR, L. Influência da presença ou ausência de folhas no enraizamento de miniestacas de cortiçeira-domato (Erythrina falcata Bentham) obtidas em sistema hidropônico. Colombo: Embrapa Florestas, 2003. 5 p. (Comunicado técnico, 89).

. Miniestaquia em sistema de hidroponia e em $\overline{\text { tubetes }}$ de cortiçeira-do-mato. Ciência Florestal, Santa Maria, v. 18, n. 1, p. 85-92, 2008.

ETCHEVERRY, A. V.; ALEMÁN, C. E. T. Reproductive biology of Erithrina falcata (Fabaceae: Papilionoideae). Biotrópica, Boston, v. 37, n. 1, p. 54-63, 2005.

FACHINELLO, J. C.; HOFFMANN, A.; NACHTIGAL, J. C. Propagação de plantas frutíferas. Brasília: Embrapa Informação Tecnológica, 2005. 221 p.

FOCHESATO, M. L.; MARTINS, F. T.; SOUZA, P. V. D.; SCHWARZ, S. F.; BARROS, I. B. I. Propagação de louro (Laurus nobilis L.) por estacas semilenhosas com diferentes quantidades de folhas e tratadas com ácido indolbutírico. Revista Brasileira de Plantas Medicinais, Botucatu, v. 8, n. 3, p. 72-77, 2006.

GRATIERI-SOSSELLA, A.; PETRY, C.; NIENOW, A. A. Propagação da corticeira do banhado (Erythrina crista-galli L.) (FABACEAE) pelo processo de estaquia. Revista Árvore, Viçosa, MG, v. 32, n. 1, p. 163-171, 2008 .

HARTMANN, H. T.; KESTER, D. E.; DAVIES JUNIOR, F. T.; GENEVE, R. L. Hartamnn and Kester's plant propagation: principles and practices. 7 . ed. New Jersey: Prentice Hall, 2002. 880 p. 
KNAPIK， J. G.; ZUFFELLATO-RIBAS， K. C.; CARPANEZZI, A. A.; TAVARES, F. R.; KOEHLER, H. $\mathrm{S}$. Influência da época de coleta e da aplicação de ácido indol butírico na propagação por estaquia da Tibouchina pulchra (Cham,) Cogn. (quaresmeira). Iheringia, Porto Alegre, v. 58, n. 2, p. 171-179, 2003.

LORENZI, H. Árvores brasileiras. 4. ed. Nova Odessa: Instituto Plantarum, 2002. v. 1. p. 219.

MINDÊLLO NETO, U. R. Estaquia herbácea de pessegueiro cv. Charme, em função de diferentes concentrações de ácido indolbutírico (AIB) e número de folhas. Revista Brasileira de Agrociência, Pelotas, v. 12, n. 1, p. 27-29, 2006.

NEVES, T. dos S.; CARPANEZZI,A.A.; ZUFFELLATORIBAS, K. C.; MARENCO, R. A. Enraizamento de corticeira-da-serra em função do tipo de estaca e variação sazonal. Pesquisa Agropecuária Brasileira, Brasília, v. 41, n. 12, p. 1699-1705, 2006.
PAIVA, H. N. de; GOMES, J. M. Propagação vegetativa de espécies florestais. Viçosa,MG: UFV, 2001. 46 p. (Série Cadernos Didáticos, 83).

PIO, R.; CHALFUN, N. N. J.; RAMOS, J. D.; GONTIJO, T. CA.; TOLEDO, M.; CARRIJO, E. P. Presença de folhas e gema apical no enraizamento de estacas herbáceas de figueira oriundas de desbrota. Revista Brasileira de Agrociência, Pelotas, v. 10, n. 1, p. 51-54, 2004.

WENDLING, I.; FERRARI, M. P.; DUTRA, L. F. Produção de mudas de cortiçeira-do-mato por miniestaquia a partir de propágulos juvenis. Colombo: Embrapa Florestas, 2005. 5 p. (Comunicado técnico, 130).

XAVIER, A.; SANTOS, G. A. dos; OlIVEIRA, M. L. de. Enraizamento de miniestaca caulinar e foliar na propagação vegetativa de cedro-rosa (Cedrela fissilis Vell.). Revista Árvore, Viçosa, MG, v. 27, n. 3, p. 351356, 2003. 